\title{
Linkage studies in NIDDM with markers near the sulphonylurea receptor gene
}

\author{
B.Stirling ${ }^{1}$, N.J.Cox ${ }^{2}$, G.I. Bell ${ }^{2}$, C. L.Hanis ${ }^{3}$, R.S.Spielman ${ }^{4}$, P.Concannon ${ }^{1,5}$ \\ ${ }^{1}$ Virginia Mason Research Center, Seattle, Washington, USA \\ ${ }^{2}$ Howard Hughes Medical Institute, University of Chicago, Chicago, Illinois, USA \\ ${ }^{3}$ School of Public Health, University of Texas, Houston, Texas, USA \\ ${ }^{4}$ University of Pennsylvania School of Medicine, Philadelphia, Pennsylvania, USA \\ ${ }^{5}$ Department of Immunology, University of Washington School of Medicine, Seattle, Washington, USA
}

\begin{abstract}
Summary The high affinity receptor for sulphonylureas, expressed on the beta cells of the pancreas, plays a crucial role in the control of insulin secretion. Mutations in the cytoplasmic domain of the sulphonylurea receptor $(S U R)$ gene that disrupt the regulation of insulin secretion have been previously described. In the present study, the potential role of genetic variation in the $S U R$ gene has been investigated in non-insulin-dependent diabetes mellitus (NIDDM) through linkage studies with microsatellite markers tightly linked to the $S U R$ gene. The microsatellite markers were typed in 346 MexicanAmerican NIDDM affected sib pairs derived from 176 families and an additional 110 ethnically and geo-
\end{abstract}

graphically matched control subjects. No evidence of linkage, based on allele sharing, or association based on allele frequencies in patients and control subjects, for any microsatellite marker and NIDDM was observed in this population. These results suggest that genetic variation in the $S U R$ gene does not play a major role in susceptibility to NIDDM in the MexicanAmerican population. [Diabetologia (1995) 38: 1479-1481]

Key words Sulphonylurea receptor, non-insulin-dependent diabetes mellitus, genetics, polymorphism, linkage mapping.
Non-insulin-dependent diabetes mellitus (NIDDM) is a complex metabolic disorder characterized by insulin resistance in peripheral tissues, and defects in insulin secretion in the pancreas. Genetic and familial factors contribute strongly to susceptibility to NIDDM. The concordance rate for NIDDM in identical twins may exceed $90 \%$ and the incidence of NIDDM in first-degree relatives of patients is also significantly increased over the prevalence in the general population [1]. Attempts to dissect the genetic

Received: 16 May 1995 and in final revised form: 15 September 1995

Corresponding author: Dr. P. Concannon, Virginia Mason Research Center, 1000 Seneca St., Seattle, WA 98101, USA Abbreviations: $S U R$, Sulphonylurea receptor; ASP, affected sib pair; IBD, identical by descent; IBS, identical by state; PHHI, persistent hyperinsulinaemic hypoglycaemia of infancy; PCR, polymerase chain reaction; NIDDM, non-insulin-dependent diabetes mellitus. contributions to NIDDM susceptibility have often focussed on specific candidate genes whose products are known to play a role in glucose metabolism.

Sulphonylurea drugs are frequently employed in the management of NIDDM. These drugs bind to a specific receptor on the beta cells of the islets and block membrane potassium channels leading to membrane depolarization and secretion of insulin [2]. Recently, the gene for the sulphonylurea receptor (SUR) expressed on beta cells has been cloned and mapped to human chromosome 11p15.1 [3]. Mutations disrupting the projected nucleotide binding domain of the molecule were identified in patients with persistent hyperinsulinaemic hypoglycaemia of infancy (PHHI) an autosomal recessive disorder characterized by unregulated insulin secretion even in the presence of severe hypoglycaemia [3]. These observations indicate that the $S U R$ protein plays a central role in the regulation of insulin secretion.

In the present study the role of genetic variation at or near the $S U R$ gene locus in NIDDM was investi- 
gated. A panel of 346 NIDDM affected sib pairs of Mexican-American origin were studied for allele sharing with microsatellite markers previously demonstrated to be tightly linked to the $S U R$ gene by linkage studies in PHHI families. No significant evidence of linkage between these markers and NIDDM was observed.

\section{Subjects and methods}

Microsatellite genotyping. Based on the corresponding nucleotide sequences present in GenBank (http:/www.ncbi.n/ m.nih.gou), primer sequences for the markers were adjusted to a standard $\mathrm{T}_{\mathrm{m}}$ of $60^{\circ} \mathrm{C}$. A touchdown polymerase chain reaction (PCR) protocol in which the annealing temperature was reduced by 1 -degree increments from $70^{\circ} \mathrm{C}$ to $60^{\circ} \mathrm{C}$ [4] was used for amplification. All amplification reactions were carried out in total volumes of $15 \mu \mathrm{l}$ using $20 \mathrm{ng}$ of genomic DNA as template and incorporating ${ }^{35} \mathrm{~S}-\mathrm{dATP}$ during the reaction. The amplification products were separated on $5 \%$ denaturing polyacrylamide gels and detected by autoradiography. All alleles were scored independently by two observers. Absolute allele sizes measured relative to reference standards on each gel were recorded.

Linkage analyses. The study population consisted of 176 sibships of Mexican-American origin from Starr County, Texas, USA. Diagnosis of diabetes was made in accordance with the National Diabetes Data Group Guidelines [5]. Sibs were classified as having NIDDM if they had an age at onset of greater than 30 years and were either currently taking blood glucoselowering medications, or had taken such medications in the past for more than 1 year. Any individuals who had taken insulin continuously since time of diagnosis were excluded. Additional clinical data such as measurements of glucose or insulin levels, or body mass index were not collected. However, previous reports suggest that fewer than $4 \%$ of diabetic patients of Mexican-American origin might be considered to have insulin-dependent diabetes [6] and a previous survey of randomly ascertained diabetic patients from Starr County in which additional clinical parameters were evaluated found only 2 of 360 who met the clinical criteria for insulin-dependent diabetes (C. L. Hanis, unpublished data). Among the families selected, there were 124 sibships with 2 affected, 37 sibships with 3 affected, 11 sibships with 4 affected, 3 sibships with 5 affected and 1 sibship with 6 affected. Thus, a total of 424 affected siblings were studied yielding a total of 346 possible affected sib pairs (ASPs). Allele frequencies for markers were estimated from genotypes in a second population of 110 randomly selected control subjects of the same geographic and ethnic origin. Evidence for linkage was assessed by two methods. In the identity by state (IBS) method of Bishop and Williamson [7], the observed numbers of ASPs sharing 2, 1, or 0 alleles IBS are compared to the values expected under an assumption of no linkage. In the method of Holmans [8], identity by descent (IBD) probabilities are estimated from the typing data and compared to expected values under no linkage.

\section{Statistical analysis}

Significance of deviations from the null hypothesis were evaluated by the chi-squared test with 2 degrees of freedom.
Table 1. Allele sharing IBS in NIDDM affected sib pairs for markers near the $S U R$ gene

\begin{tabular}{lllllll}
\hline Marker & $\theta^{\text {a }}$ & Data & \multicolumn{3}{c}{ Allele sharing } & \multirow{2}{*}{$\chi^{2}$} \\
\cline { 3 - 6 } \cline { 3 - 5 } & & & IBS 2 & IBS 1 & IBS 0 & \\
\hline D11S1338 & \multirow{2}{*}{0.11} & Observed & 134 & 183 & 22 & 1.9 \\
D11S921 & & Oxpected & 142 & 171 & 26 & \\
& & Exserved & 160 & 151 & 35 & 8.53 \\
D11S902 & & Obsected & 153 & 170 & 23 & \\
& 0.12 & Expected & 126 & 170 & 42 & 0.75 \\
D11S929 & & Observed & 119 & 178 & 39 & \\
& & Expected & 107 & 178 & 43 & 2.61 \\
\hline
\end{tabular}

${ }^{a}$ Recombination fraction between adjacent markers

\section{Results}

The gene responsible for PHHI, now identified as $S U R$, had been previously mapped to chromosome $11 \mathrm{p}$ by linkage. Tight linkage with PHHI was reported with the markers D11S921 and D11S902 [9, 10]. Evidence of association, suggestive of close physical linkage was reported for alleles at D11S921 [9]. These two markers could not be ordered by linkage. An examination of the Genethon database (http:// www.genethon.fr) indicated that they co-localized on two YAC clones with a maximum physical separation of 890 kilobases.

D11S902 and D11S921, as well as the flanking markers D11S1338 and D11S929, were typed in a panel of 346 NIDDM ASPs currently being used for a genome-wide search for NIDDM susceptibility genes. The numbers of marker alleles that shared IBS were tallied and compared to expected values based on allele frequencies estimated from the random control group (Table 1). One marker, D11S921, revealed a modestly significant difference between observed and expected values $\left(\chi^{2}=8.53\right.$, with $2 d f$, $p=0.014)$. However, the magnitude of the observed difference was largely due to an increase in the sharing of 0 alleles IBS category, an observation inconsistent with linkage. Indeed, a second analysis of the date by the IBD method [8] provided no evidence of linkage at D11S921 $\left(\chi^{2}=1.88\right.$, with $2 d f, 0.3<p$ $<0.4$ ) (Table 2). Finally, a comparison of the allele frequencies for the markers in the NIDDM sibs and the random control group provided no evidence of any allelic associations with NIDDM (data not shown).

\section{Discussion}

NIDDM is characterized by a progressive loss of beta-cell function, i.e. insulin secretion, in the presence of increasing hyperglycaemia and insulin resistance. Thus, genes whose products regulate insulin secretion are potential candidate NIDDM susceptibil- 
Table 2. Allele sharing IBD in NIDDM affected sib pairs for markers near the SUR gene

\begin{tabular}{lllllll}
\hline Marker & $\theta^{\text {a }}$ & Data & \multicolumn{3}{c}{ Allele sharing } & \multirow{2}{*}{$\chi^{2}$} \\
\cline { 4 - 6 } & & & IBD 2 & IBD 1 & IBD 0 & \\
\hline D11S1338 & \multirow{2}{*}{0.11} & Estimated & 134 & 183 & 22 & 1.48 \\
Expected & 139 & 172 & 27 & \\
& & Estimated & 160 & 151 & 24 & \multirow{2}{*}{1.88} \\
D11S902 & & Expected & 150 & 163 & 22 & \\
& \multirow{2}{*}{0.12} & Estimated & 126 & 170 & 42 & \multirow{2}{*}{0.75} \\
Expected & 120 & 178 & 40 & \\
& & Estimated & 119 & 172 & 41 & 3.34 \\
& & Expected & 106 & 176 & 50 & \\
\hline
\end{tabular}

${ }^{a}$ Recombination fraction between adjacent markers

ity genes. The recent cloning of the $S U R$ gene and the observation that mutations in the gene are responsible for PHHI, identify $S U R$ as a gene crucial to the regulation of insulin secretion. In this study, the possibility that genetic variation in the $S U R$ gene might contribute to NIDDM susceptibility was evaluated by linkage studies in affected sib pairs of MexicanAmerican origin. No significant evidence of linkage or association with NIDDM was detected with microsatellite markers tightly linked to the SUR gene. These results are inconsistent with a major role for genetic variation in SUR in NIDDM susceptibility in the Mexican-American population.

Acknowledgements. This work was supported by grants DK47494 to P. C.; DK47486, DK20595 and HHMI to G.I.B.; DK47481 to R.S.S.; and DK47487 to C. L.H.

\section{References}

1. Rich SS (1990) Mapping genes in diabetes: genetic epidemiological perspective. Diabetes 39: 1315-1319

2. Ashcroft SJ, Ashcroft FM (1990) Properties and functions of ATP-sensitive K-channels. Cell Signal 2: 197-214

3. Thomas PM, Cote GJ, Wohlik N et al. (1995) Mutations in the sulfonylurea receptor gene in familial persistent hyperinsulinemic hypoglycemia of infancy. Science 268: 426429

4. Don RH, Cox PT, Wainwright BJ, Baker K, Mattick JS (1991) 'Touchdown' PCR to circumvent spurious priming during gene amplification. Nucl Acids Res 19: 4008

5. National Diabetes Data Group (1979) Classification and diagnosis of diabetes mellitus and other categories of glucose intolerance. Diabetes 28: 1039-1057

6. Stern MP, Rosenthal M, Haffner SM, Hazuda HP, Franco LJ (1984) Sex difference in the effects of sociocultural status on diabetes and cardiovascular risk factors in Mexican Americans. The San Antonio Heart Study. Am J Epidemiol 120: 834-851

7. Bishop DT, Williamson JA (1990) The power of identityby-state methods for linkage analysis. Am J Hum Genet 46: 219-221

8. Holmans P (1993) Asymptotic properties of affected-sibpair linkage analysis. Am J Hum Genet 52: 362-374

9. Glaser B, Chiu KC, Anker R et al. (1994) Familial hyperinsulinism maps to chromosome $11 \mathrm{p} 14-15.1,30 \mathrm{cM}$ centromeric to the insulin gene. Nature Genet 7:185-188

10. Thomas PM, Cote GJ, Hallman DM, Mathews PM (1995) Homozygosity mapping, to chromosome $11 \mathrm{p}$, of the gene for familial persistent hyperinsulinemic hypoglycemia of infancy. Am J Hum Gent 56: 416-421 